EUROPEAN ORGANIZATION FOR NUCLEAR RESEARCH

European Laboratory for Particle Physics

Large Hadron Collider Project

LHC Project Report 317

\title{
ECONOMICS OF LARGE HELIUM CRYOGENIC SYSTEMS: EXPERIENCE FROM RECENT PROJECTS AT CERN
}

\author{
S. Claudet, Ph. Gayet, Ph. Lebrun, L. Tavian and U. Wagner
}

\begin{abstract}
Large projects based on applied superconductivity, such as particle accelerators, tokamaks or SMES, require powerful and complex helium cryogenic systems, the cost of which represents a significant, if not dominant fraction of the total capital and operational expenditure. It is therefore important to establish guidelines and scaling laws for costing such systems, based on synthetic estimators of their size and performance. Although such data has already been published for many years, the experience recently gathered at CERN with the LEP and LHC projects, which have de facto turned the laboratory into a major world cryogenic center, can be exploited to update this information and broaden the range of application of the scaling laws. We report on the economics of $4.5 \mathrm{~K}$ and $1.8 \mathrm{~K}$ refrigeration, cryogen distribution and storage systems, and indicate paths towards their cost-to-performance optimisation.
\end{abstract}

LHC Division

Presented at the 1999 Cryogenic Engineering and International Cryogenic Materials Conference

(CEC-ICMC'99), 12-16 July 1999, Montreal, Canada

Administrative Secretariat

LHC Division

CERN

CH - 1211 Geneva 23

Switzerland

Geneva, 1 December 1999 


\title{
ECONOMICS OF LARGE HELIUM CRYOGENIC SYSTEMS: EXPERIENCE FROM RECENT PROJECTS AT CERN
}

\author{
S. Claudet, Ph. Gayet, Ph. Lebrun, L. Tavian and U. Wagner \\ LHC Division, CERN \\ 1211 Geneva 23, Switzerland
}

\begin{abstract}
Large projects based on applied superconductivity, such as particle accelerators, tokamaks or SMES, require powerful and complex helium cryogenic systems, the cost of which represents a significant, if not dominant fraction of the total capital and operational expenditure. It is therefore important to establish guidelines and scaling laws for costing such systems, based on synthetic estimators of their size and performance. Although such data has already been published for many years, the experience recently gathered at CERN with the LEP and LHC projects, which have de facto turned the laboratory into a major world cryogenic center, can be exploited to update this information and broaden the range of application of the scaling laws. We report on the economics of $4.5 \mathrm{~K}$ and $1.8 \mathrm{~K}$ refrigeration, cryogen distribution and storage systems, and indicate paths towards their cost-to-performance optimisation.
\end{abstract}

\section{LARGE-SCALE CRYOGENICS AT CERN}

On the spur of increasing demands from forefront accelerator and detector projects for high-energy physics, which all make intensive use of superconducting devices electromagnets and acceleration cavities - CERN has become over the last decade a major center in helium cryogenics (Figure 1), with 19 refrigerators in operation all over the site, out of which 9 with capacities ranging from 0.8 to $12 \mathrm{~kW} @ 4.5 \mathrm{~K}^{1}$.

LEP, the 26.7-km circumference electron-positron collider in operation since 1989, features four underground experimental areas equipped with high-luminosity insertions using superconducting quadrupoles, as well as large spectrometer solenoids, two of which also are superconducting. All these devices are cooled at $4.5 \mathrm{~K}$ by dedicated helium refrigerators and cryogenic systems ${ }^{2}$, now totalising ten years of current operation. Over the nineties, the beam energy of LEP has gradually been increased by the addition of 288 superconducting acceleration cavities ${ }^{3}$, installed in four strings, each 500-m long and cooled by a dedicated $12 \mathrm{~kW} @ 4.5 \mathrm{~K}$ cryogenic plant ${ }^{4}$, through some $2 \mathrm{~km}$ of gas-shielded 


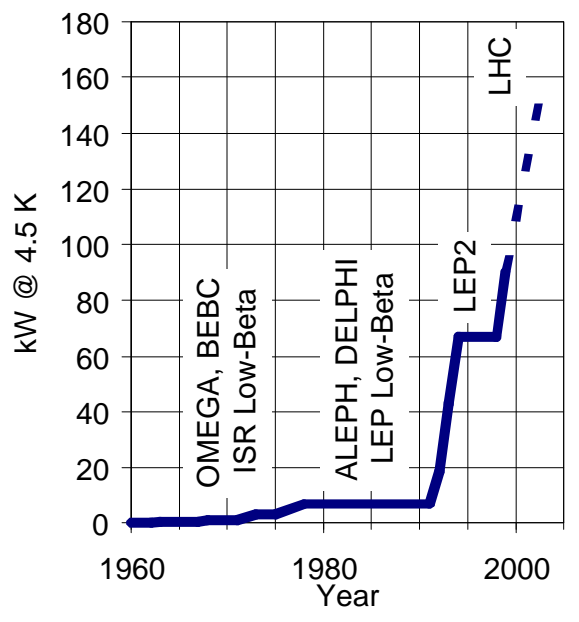

Figure 1. Installed capacity at CERN

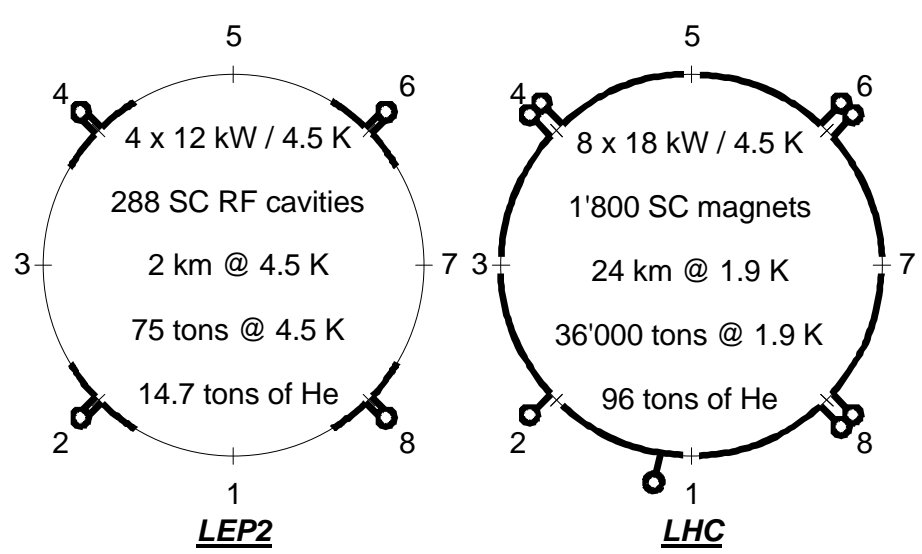

Figure 2. LEP2 and LHC cryogenic systems

cryogenic distribution lines ${ }^{5}$. This constitutes the largest distributed cryogenic system in the world, and is being routinely operated as an integral part of the LEP2 collider ${ }^{6,7}$.

The trend towards larger, more powerful systems will continue in the coming years with the procurement, installation and commissioning of the cryogenic system for the LHC (Figure 2), a high-energy, high-luminosity proton and ion collider using twin-aperture, high-field superconducting magnets operating in superfluid helium below $1.9 \mathrm{~K}^{8}$. Due to start operation in 2005, the LHC will reuse the LEP tunnel and infrastructure, among which the four large refrigerators, which have been upgraded in preparation for this purpose. It will also require four new $18 \mathrm{~kW} @ 4.5 \mathrm{~K}$ refrigerators, presently under construction in European industry ${ }^{9}$, as well as eight $2.4 \mathrm{~kW} @ 1.8 \mathrm{~K}$ refrigeration units, partially fed from the $4.5 \mathrm{~K}$ cryogenic plants. The LHC cryogenic system will therefore add, to its sheer size and installed power, the qualitative novelty of large-scale cryogenics at $1.8 \mathrm{~K}$, which has required the conduction of a dedicated development programme over the past years ${ }^{10}$. The LHC will also be characterised by its huge cold mass and large helium inventory, both of which strongly impact on the technical and economical choices of the cryogenic system.

The demanding projects briefly mentioned above have prompted us to devote significant effort to the technical and economical optimisation of their cryogenic systems, at the level of design, technical specification and industrial procurement of equipment, as well as methods for reliable operation and preventive maintenance. Conversely, they have provided us with detailed, up-to-date information on the economic aspects of large helium cryogenic systems, which we try and report in the following, confronting it when relevant with previously published material in the field.

\section{ECONOMICS OF HELIUM REFRIGERATORS}

\section{Technical Scope}

Since the now classical studies by Strobridge ${ }^{11,12}$, the capital cost of helium refrigerators has been surveyed and tentatively correlated with a single performance estimator, originally the installed compressor power, and more recently the refrigeration capacity produced at $4.5 \mathrm{~K}^{13,14}$. This approach has the merit of extreme simplicity, but - as a consequence - requires careful application for large, complex refrigerators such as those of CERN, which for reason of site layout and underground implantation, often feature several cold boxes with interconnecting lines, and in most cases, provide cooling duties isothermal and non-isothermal - at a variety of temperature levels ${ }^{15}$. 


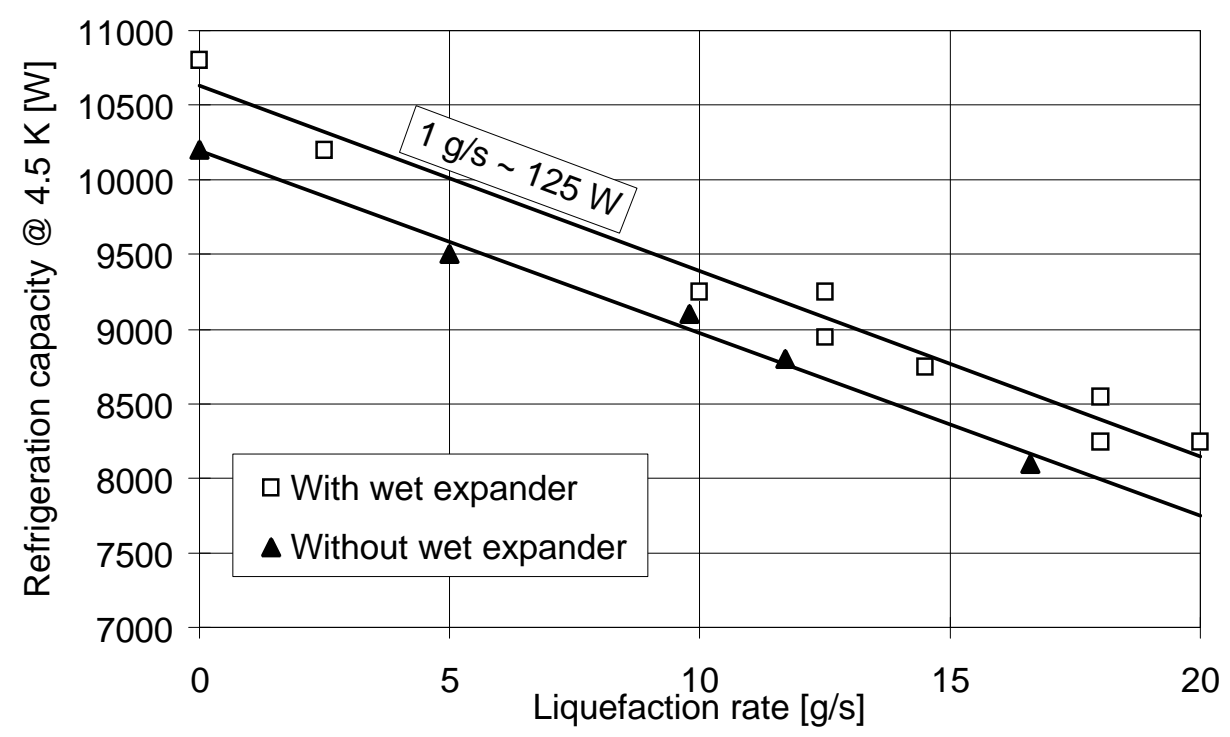

Figure 3. Measured liquefaction rate versus refrigeration capacity of $12 \mathrm{~kW} @ 4.5 \mathrm{~K}$ refrigerators

In the following, we shall therefore only consider multi-kW @ $4.5 \mathrm{~K}$ cryogenic plants of modern design, based on modified Claude cycles, using two stages of oil-injected screw compressors with intercooling, an oil-removal system composed of three stages of coalescing filters and an adsorber, coldboxes based on brazed aluminium plate-fin heat exchangers and turbo-expanders with helium-gas bearings. In line with widespread practice in Europe, the helium refrigeration cycles do not use liquid nitrogen precooling on a permanent basis, and, in cases when the cryogenic plants considered do feature a largecapacity liquid nitrogen precooler used for cooldown of the load, its specific cost has been substracted from the quoted numbers. A peculiarity of the large LEP refrigerators is their "split-coldbox" design. As a result, the "upper" and "lower" coldboxes are connected by compound cryogenic lines spanning their vertical separation, and installed in the technical shafts; the specific cost of these lines must also clearly be removed from significant cost estimates for "normal" cryogenic plants. Instrumentation and actuators, fault diagnosis and safety interlocks are included; however the process control hardware and software, which were purchased separately for the sake of uniformity among refrigerators of different origins, do not form part of the following estimates.

In order to approach overall exergetic efficiency, the LEP and LHC cryogenic systems make use of several levels of temperature for heat interception, each of which requiring its own cooling duty. For the sake of comparison, the multiple cooling duties produced by the cryogenic plants have been converted, by isoexergetic equivalence, into isothermal refrigeration capacity at $4.5 \mathrm{~K}$. We are fully aware of the weakness of this modus operandi, particularly when trading liquefaction and refrigeration loads (Figure 3), but nevertheless find it an acceptable compromise, at least for cryogenic plants supplying the largest fraction of their exergetic refrigeration capacity at $4.5 \mathrm{~K}$.

\section{Capital Cost of 4.5 K Refrigerators}

The capital cost of the different CERN refrigerators was actualized to $1998 \mathrm{CHF}$ following ${ }^{16}$. Figure 4 also shows equation (1) given in $^{14}$ that was indexed from 1997 USD to $1998 \mathrm{USD}^{17}$ and converted into $1998 \mathrm{CHF}$.

$$
\operatorname{Cost}[1998 \mathrm{MCHF}]=2.6 *(\text { Capacity }[\mathrm{kW} @ 4.5 \mathrm{~K}])^{0.7}
$$

Our best practical fit of the data is represented by equation (2)

$$
\operatorname{Cost}[1998 \mathrm{MCHF}]=2.2 *(\text { Capacity }[\mathrm{kW} @ 4.5 \mathrm{~K}])^{0.6}
$$




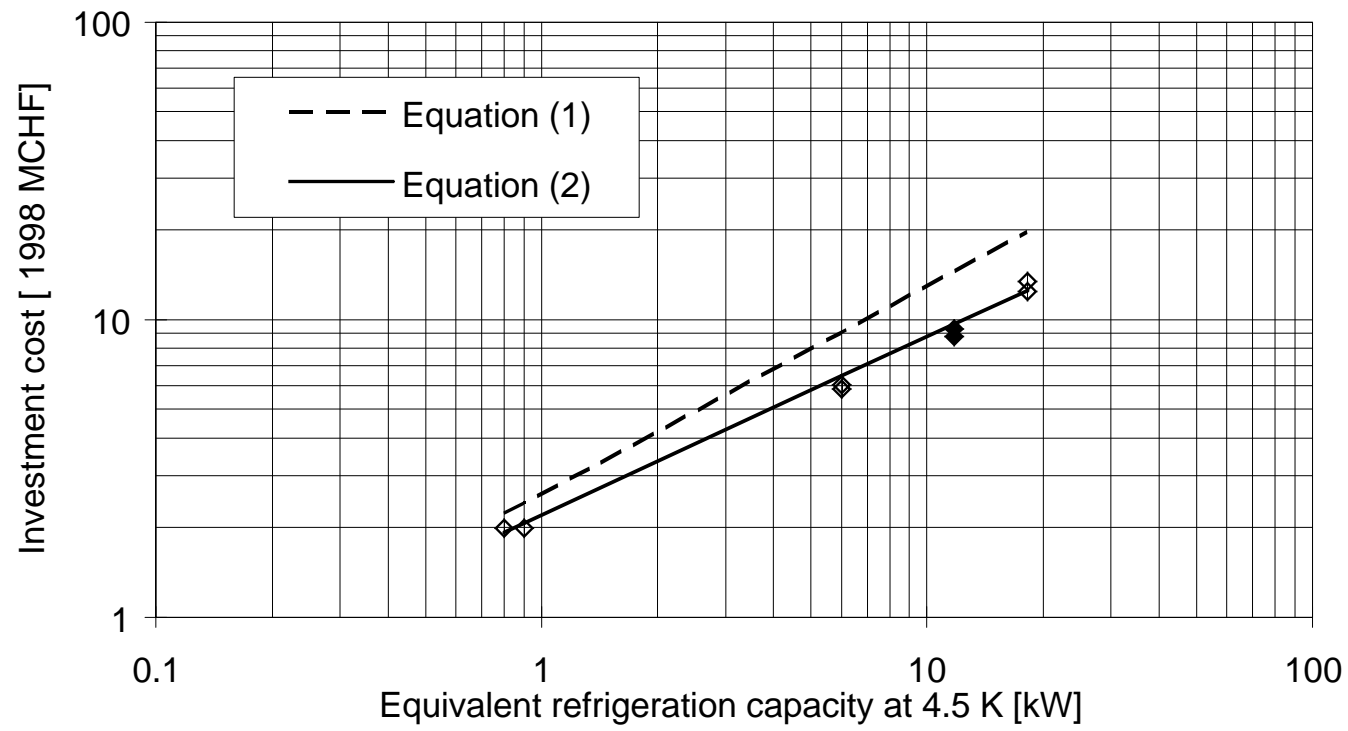

Figure 4. Investment cost of $4.5 \mathrm{~K}$ refrigerators at CERN versus equivalent capacity

\section{Efficiency, Operation and Maintenance}

As the CERN particle accelerators and experiments operate round-the-clock on a yearly basis - except for a 3- to 4-month long winter shut-down scheduled in the period of peaking electricity demand - it is legitimate to take operating expenses into consideration, in view of a global cost optimisation ${ }^{9}$. The key ingredients of such an optimisation are:

- the thermodynamic efficiency (C.O.P.) of the refrigerators,

- the annual number of hours of operation of the refrigerators, which has been taken at 6600 to account for the fact that cryogenics is usually required to start well in advance of physics (for equipment tests), and to terminate later (for managing and storing the helium inventory before shut-down),

- the number of years over which the integrated costs are calculated. For the purpose of equipment design, the technical lifetime of the LHC has been set at 20 years. However, in view of the fact that the operating costs over this period have not been actualised, the operation lifetime for the purpose of economic optimisation has been taken at 10 years,

- the mix of operational modes - each with different cooling duties and corresponding variable electrical power consumption - encountered in a typical year of operation,

- the marginal cost of electricity, based on the unit price - averaged over the annual period of operation to smear out strong seasonal price variations - and including externalities such as the marginal cost contributions of transport and conversion from $400 \mathrm{kV}$ to $3.3 \mathrm{kV}$, as well as of rejection of the dissipated heat to the environment, globally amounting to $60 \mathrm{CHF} / \mathrm{MWh}^{18}$,

- the cost of preventive maintenance, including spare parts and manpower. The cost of spare parts is mostly related to compressor maintenance and can be estimated for LEP2 at $2.5 \%$ per year of the capital cost of the compressor system. The manpower expenditure is equally distributed between the mechanical maintenance of the compressors (3\% per year of the compressor capital cost) and the maintenance of instrumentation (80 CHF per channel per year),

- the cost of helium, which depends on the nature of the load. For a closed circuit such as LEP2 with a global helium inventory of $14700 \mathrm{~kg}$, the annual losses amount to about $3400 \mathrm{~kg}$ (excluding accidental events),

- the cost of manpower for operation, which strongly depends on the organisation of the operating team and the level of automation ${ }^{7}$. 


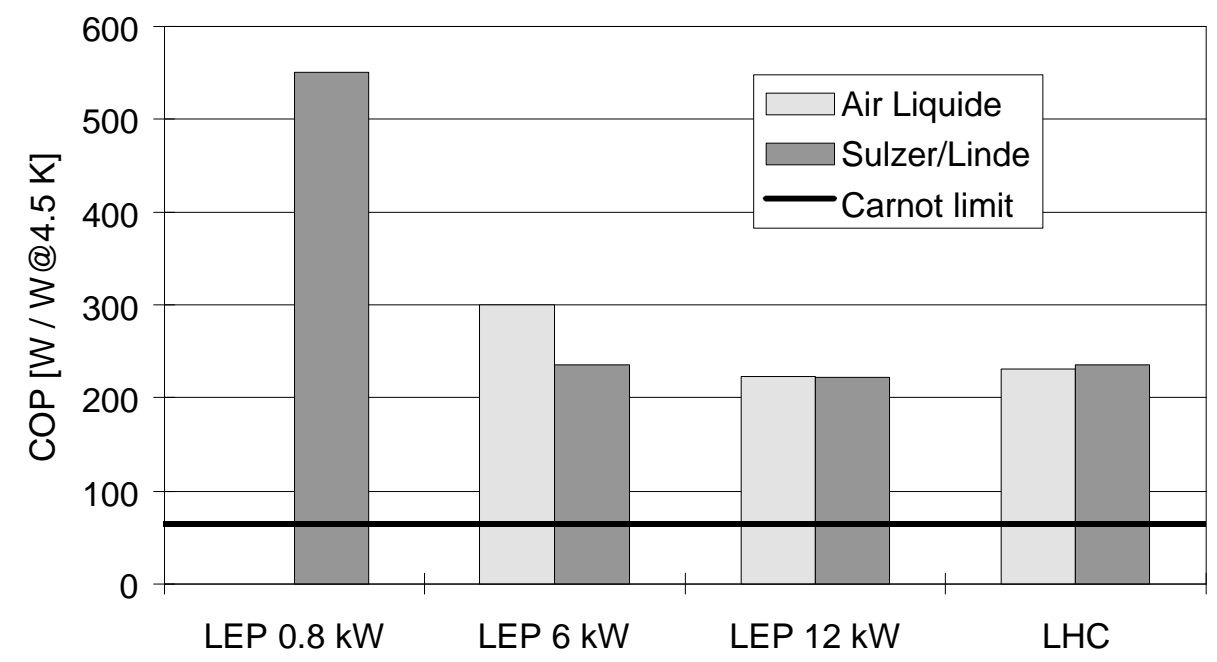

Figure 5. Coefficient of performance of $4.5 \mathrm{~K}$ refrigerators at CERN

As the operation costs are dominated by that of electricity, the integrated price estimates used for the purpose of comparing offers and adjudicating contracts included only capital and electricity costs 9 . An expected result of the large relative weight given to electricity costs, was to drive the refrigerator designs to higher efficiency, now amounting to about 220 W/W @ $4.5 \mathrm{~K}$ or $30 \%$ of the Carnot cycle (Figure 5). This was achieved not so much by improvement of efficiency of single components, such as heat exchangers or turbo-expanders, than by the arrangement of these components in carefully optimised cycles $^{19}$. A less expected consequence of this technical-economical incentive policy has been to reduce the capital investment of the refrigerators. Contrary to the previously established belief that more efficient refrigerators were more expensive to build - although cheaper to operate -, this approach demonstrated that increasing the efficiency for the same, specified refrigeration output, enables to reduce the process flow-rate, and hence to down-size the heat exchangers, to gain on the size of the coldbox and compressors, and even in some cases to make the economy of one compressor unit, all of which result in overall savings in capital as well as in running costs.

\subsection{K REFRIGERATION}

Producing large capacity refrigeration at $1.8 \mathrm{~K}^{20}$ requires the use of cold compressors ${ }^{21}$ to compress helium up to a pressure at which warm compressors become feasible. Figure 6 shows a generic $1.8 \mathrm{~K}$ refrigeration scheme, which can be analysed in two parts. The first part concerns the $1.8 \mathrm{~K}$ refrigeration unit containing the cold compressors, the warm compressor station and a counter-flow heat exchanger. The second part is a standard $4.5 \mathrm{~K}$ refrigerator, producing non-isothermal refrigeration between $4.5 \mathrm{~K}$ and a temperature $\mathrm{Tr}$, which directly depends on the cold compressor pressure ratio (CPR). Figure 7 shows the corresponding equivalent exergetic load at $4.5 \mathrm{~K}$, as a function of the CPR. The investment and operation cost of this second part can be assessed as for other $4.5 \mathrm{~K}$ refrigerators. Figure 8 shows the relative cost of $1.8 \mathrm{~K}$ refrigeration as a function of the CPR. The investment and operation costs of the $1.8 \mathrm{~K}$ part decrease with increasing CPR. This reduction is however compensated by the investment and operation costs of the $4.5 \mathrm{~K}$ part. For CPR above 25, the total cost is about constant and other factors, such as compactness or operational flexibility determine the technical choice. Figure 9 shows the investment costs as a function of the $1.8 \mathrm{~K}$ refrigeration capacity. The total cost of $1.8 \mathrm{~K}$ refrigeration for the LHC is lower than given by this model, due to the use of larger, more cost effective $4.5 \mathrm{~K}$ cryogenic plants, which also provide other cooling duties. 


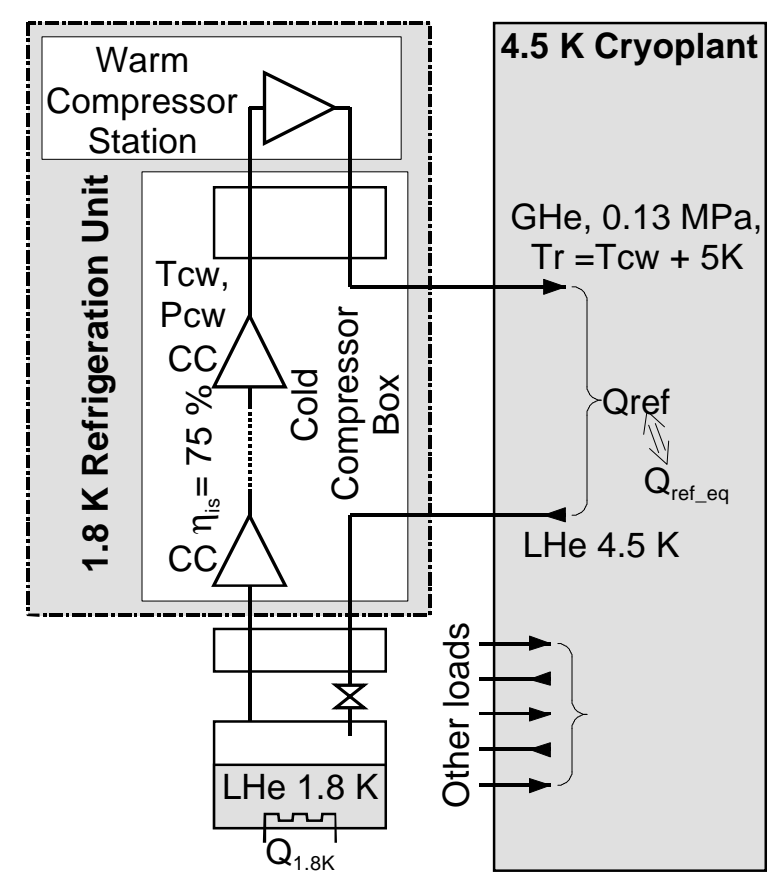

Figure 6. Generic $1.8 \mathrm{~K}$ refrigeration scheme

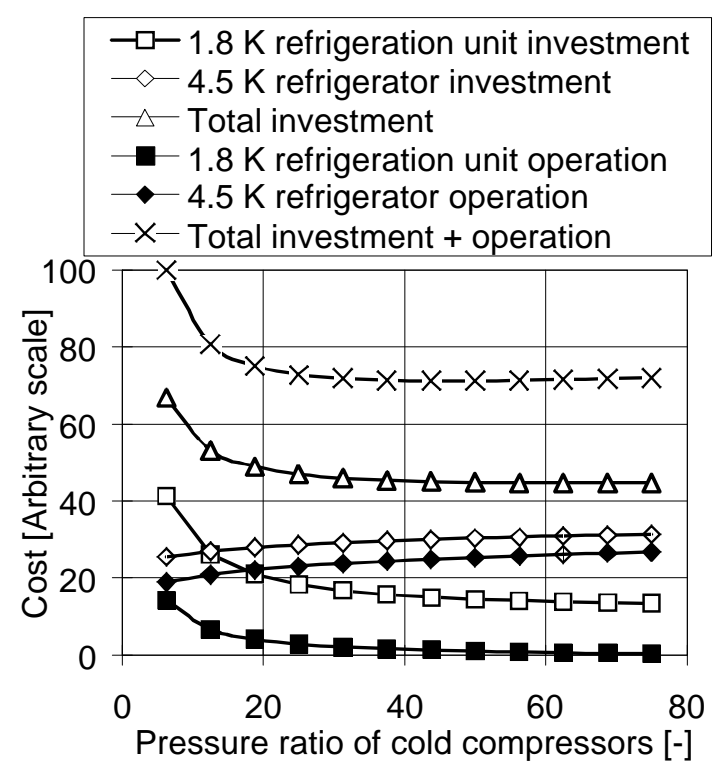

Figure 8. Cost structure of $1.8 \mathrm{~K}$ refrigeration

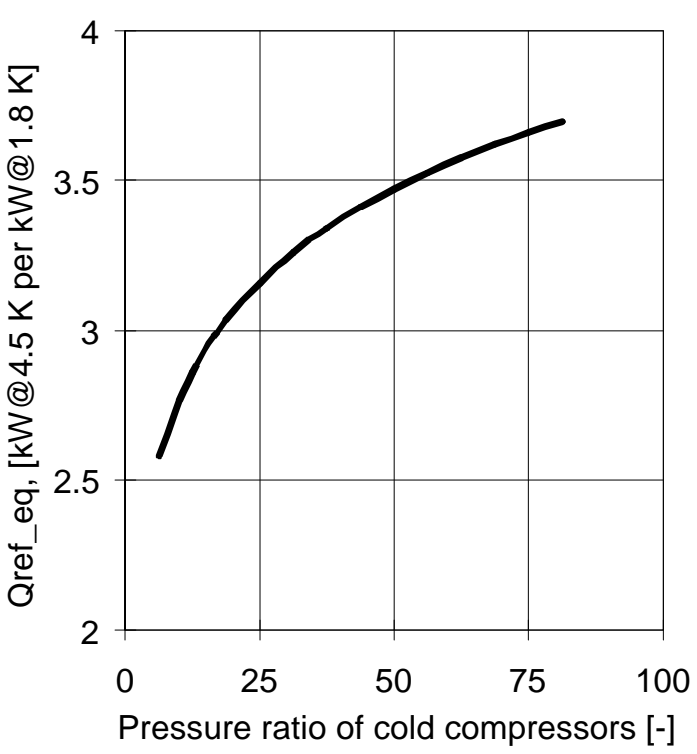

Figure 7. Equivalent $4.5 \mathrm{~K}$ load induced by $1.8 \mathrm{~K}$ refrigeration unit

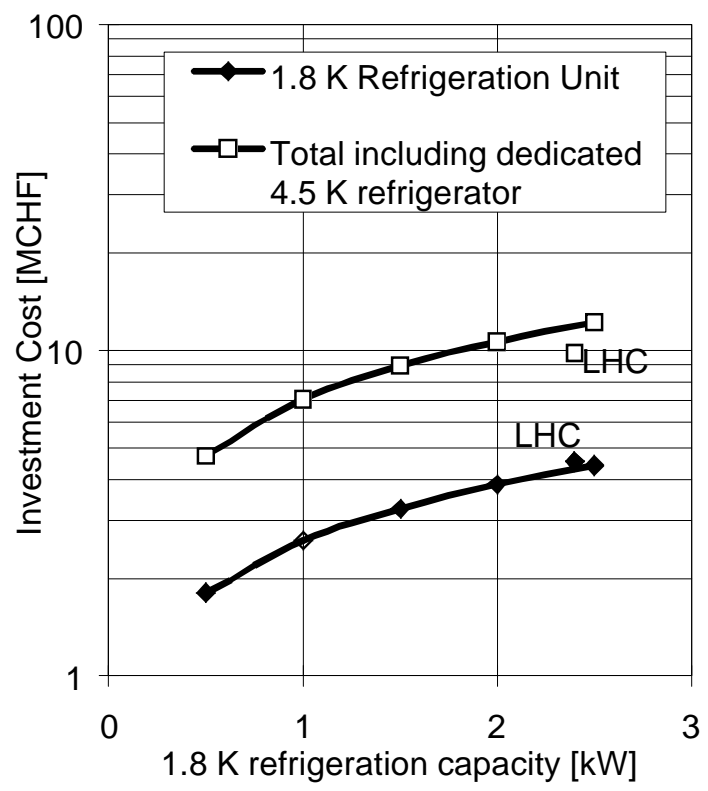

Figure 9. Investment cost of $1.8 \mathrm{~K}$ refrigeration

\section{HELIUM STORAGE AND INVENTORY MANAGEMENT}

For closed-circuit cryogenic systems which encounter relatively long shutdown periods without possibility of re-liquefaction, and fast helium discharge (magnet quenches), medium-pressure (MP) storage at $2 \mathrm{MPa}$ and ambient temperature is commonly used. Figure 10 shows the cost of MP storage as a function of unit geometrical volume for carbon-steel storage vessels. The cost, driven by that of the material, was estimated for cylindrical and spherical geometries, including transportation and site erection. For large vessels, it matches the data in $^{22}$. Due to the huge helium inventory of the LHC, the MP storage capacity is deliberately limited to $50 \%$ of the total, in order to minimise investment. Consequently, for cooldown and warmup of the machine, it is foreseen to shuffle helium from the LHC to the market, in the framework of a "virtual storage" type contract. 


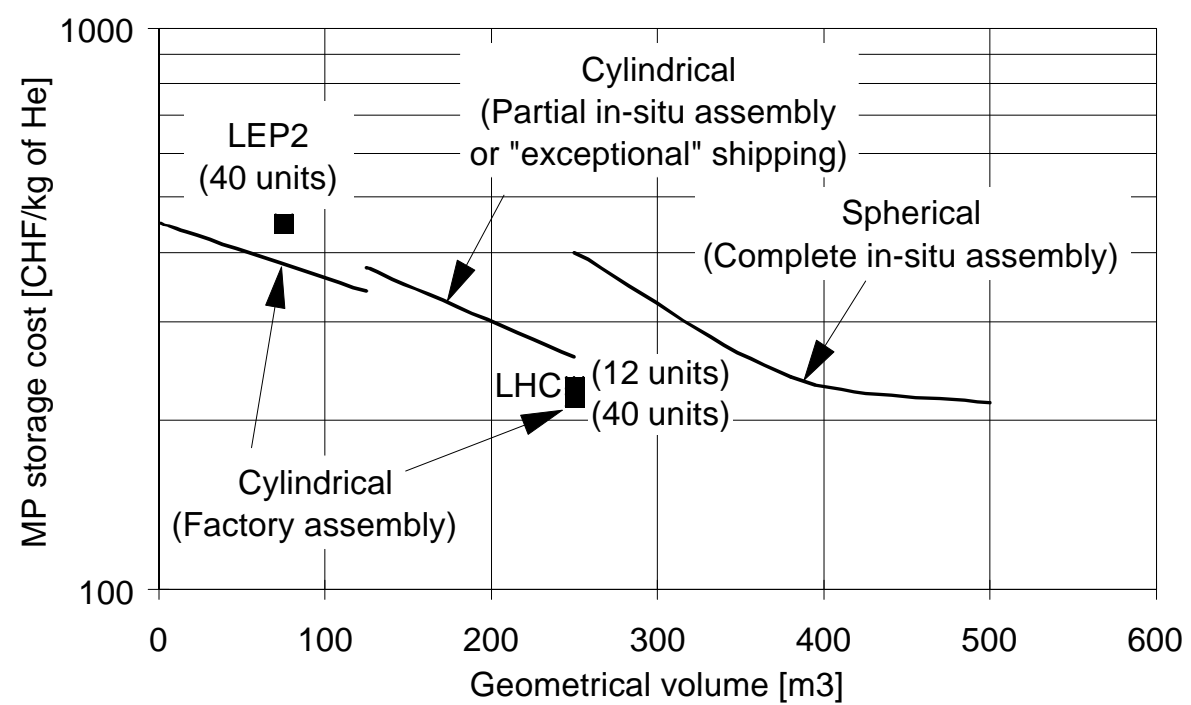

Figure 10. Cost of MP storage (2MPa, ambient temperature)

\section{CRYOGENIC DISTRIBUTION LINES AND PIPEWORK}

The cryogenic lines in the kilometre range used in CERN accelerators exhibit a variety of types, sizes, design choices and site layouts. While seeking a general estimator of their cost, we propose to use, as a basis, the cost of stainless steel piping $(7.5 \mathrm{CHF} / \mathrm{kg}$ ), multiplied by specific "cost multipliers" such as shown in Table 1. The relative cost of engineering is about constant for pipework at ambient temperature, whereas it strongly depends on overall tonnage and siting considerations for cryogenic distribution lines. The cost of singularities, such as valves or bayonet connections, should be added to the estimate.

Table 1. Cost structure of cryogenic lines and pipework: material cost multipliers

\begin{tabular}{lcc}
\hline & Ambient pipework & Cryogenic lines \\
\hline Material cost & 1.0 & 1.5 \\
Engineering & & $6-8$ \\
Installation & \multirow{2}{*}{1.2} & $2.5-3.0$ \\
Tests & & $0.5-0.8$ \\
\hline Total & 2.2 & $10.5-13.3$ \\
\hline
\end{tabular}

\section{CONCLUSION}

With the advent of industrial-size helium cryogenic systems, ancillary to large research or industrial projects using applied superconductivity, a significant fraction of the total expenditure resides in the cost of cryogenics alone. In view of CERN's long experience in designing, procuring and operating several such large-capacity cryogenic systems, we are now able to assess their main economic features, and estimate their cost with engineering precision. As a result, the main procurement contracts for the cryogenics of the LHC, which have been adjudicated to specialised industry on a competitive basis over the last two years, generally fall within budget estimates, an important asset for the construction and funding on schedule of the project. 


\section{ACKNOWLEDGMENTS}

The results presented here were obtained over more than a decade of hard work by our colleagues from the Accelerator Cryogenics and Experiment \& Test Areas Cryogenics Groups at CERN. The competence, competitiveness and interest of specialised industry in CERN's projects constitutes an essential ingredient of success, which we also wish to acknowledge.

\section{REFERENCES}

1. J.P. Dauvergne, D. Delikaris, W. Erdt, D. Güsewell, F. Haug, Ph. Lebrun, G. Passardi, J.M. Rieubland, J. Schmid \& G. Winkler, Application of liquid-helium cryoplants at CERN, Adv. Cryo. Eng. 39A:539 (1994)

2. J.P. Dauvergne, M. Firth, A. Juillerat, Ph. Lebrun \& J.M. Rieubland, Helium cryogenics at the LEP experimental areas, Adv. Cryo. Eng. 35B:901 (1990)

3. M. Barranco-Luque, J.P. Dauvergne, W. Erdt, P. Frandsen, D. Güsewell, F. Haug, A. Juillerat, G. Passardi, J. Schmid \& G. Winkler, The refrigeration system for the LEP energy upgrade, Cryogenics 30 ICEC Supplement:136 (1990)

4. S. Claudet, W. Erdt, P. Frandsen, Ph. Gayet, N. Solheim, Ch. Titcomb \& G. Winkler, Four 12 kW / 4.5 K cryoplants at CERN, Cryogenics 34 ICEC Supplement:99 (1994)

5. D. Güsewell, M. Barranco-Luque, S. Claudet, W. Erdt, P. Frandsen, Ph. Gayet, J. Schmid, N. Solheim, Ch. Titcomb \& G. Winkler, Cryogenics for the LEP200 superconducting cavities at CERN, in "Proc. PAC'93 Washington" 4:2956 (1993)

6. M. Barranco-Luque, S. Claudet, Ph. Gayet, N. Solheim \& G. Winkler, Operation of the cryogenic system for the superconducting cavities of LEP, in: "Proc. ICEC16 Kitakyushu", Vol. 1, T. Haruyama, T. Mitsui \& K. Yamafuji, eds., Elsevier Science, Oxford, New York \& Tokyo (1997), p. 103

7. N. Bangert \& Ph. Gayet, Operation of the four $12 \mathrm{~kW}$ at $4.5 \mathrm{~K}$ refrigerators for LEP, paper presented at this conference

8. Ph. Lebrun, Superfluid helium cryogenics for the Large Hadron Collider project at CERN, Cryogenics 34 ICEC Supplement:1 (1994)

9. S. Claudet, Ph. Gayet \& U. Wagner, Specification of four new large $4.5 \mathrm{~K}$ refrigerators for the LHC, paper presented at this conference

10. Ph. Lebrun, L. Tavian \& G. Claudet, Development of large-capacity refrigeration at $1.8 \mathrm{~K}$ for the Large Hadron Collider at CERN, in: "Proc. Kryogenika'96 Praha", IIR-IIF, Prague (1996), p.54

11. T.R. Strobridge, IEEE Trans. Nucl. Sc. NS-16 3:1:1104 (1969)

12. T.R. Strobridge, "Cryogenic Refrigerators: an Updated Survey", NBS Technical Note 655 (1974)

13. M.A. Green, R.A. Byrns \& S.J. St. Lorant, Estimating the cost of superconducting magnets and the refrigerators needed to keep them cold, Adv. Cryo. Eng. 37A:637 (1992)

14. R.A. Byrns \& M.A. Green, An update on estimating the cost of cryogenic refrigeration, Adv. Cryo. Eng. 43B:1661 (1998)

15. Ph. Lebrun, G. Riddone, L. Tavian \& U. Wagner, Demands in refrigeration capacity for the Large Hadron Collider, in: "Proc. ICEC16 Kitakyushu", Vol. 1, , T. Haruyama, T. Mitsui \& K. Yamafuji, eds., Elsevier Science, Oxford, New York \& Tokyo (1997), p. 95

16. G. Lindecker, CERN materials index (excluding electricity, fluids and telecom), private communication

17. Gross Domestic Product Deflator Inflation Calculator, NASA Johnson Space Center, http://www.jsc.nasa.gov/bu2/inflateGDP.html

18. Ph. Lebrun, "Estimation du Coût Marginal de l'Energie Consommée par la Cryogénie du LHC", LHC Project Note 92 (1997)

19. M. Barranco-Luque, S. Claudet, W. Erdt, P. Frandsen, Ph. Gayet, D. Güsewell, Ph. Lebrun, J. Schmid, N. Solheim, Ch. Titcomb, U. Wagner \& G. Winkler, Conclusions from procuring, installing and commissioning six large-scale helium refrigerators at CERN, Adv. Cryo. Eng. 41A:761 (1996)

20. F. Millet, P. Roussel, L. Tavian \& U. Wagner, A possible $1.8 \mathrm{~K}$ refrigeration cycle for the Large Hadron Collider, Adv. Cryo. Eng. 43A:387 (1998)

21. A. Bézaguet, $\mathrm{Ph}$. Lebrun \& L. Tavian, Performance assessment of industrial prototype cryogenic helium compressors for the Large Hadron Collider, in: "Proc. ICEC17 Bournemouth", D. Dew-Hugues, R.G. Scurlock \& J.H.P. Watson, eds., IoP, Bristol \& Philadelphia (1998), p. 145

22. G.Y. Robinson Jr., Economics of cryogenic systems for superconducting magnets, Adv. Cryo. Eng. 25: 342 (1980) 